\title{
O CRIME DE AMEAÇA NO ÂMBITO DOMÉSTICO: UMA ANÁLISE DA IMPUNIDADE DA LEI MARIA DA PENHA A PARTIR DE ESTUDOS DE FLUXOS
}

\author{
Douglas da Silva Araújo ${ }^{75}$ \\ Patrícia Borba Vilar Guimarães ${ }^{76}$ \\ Yanko Marcius de Alencar Xavier ${ }^{77}$
}

Recebido em: 07/12/2018

Aprovado em: 18/09/2019

\begin{abstract}
RESUMO
O presente estudo pretendeu identificar quais fatores são preponderantes no fluxo dos processos em trâmite no $2^{\circ}$ Juizado da Violência Doméstica e Familiar Contra a Mulher de Natal/RN, instância que compõe o sistema da justiça criminal, para aferir os níveis de impunidade do crime de ameaça quando cometido no âmbito da Lei Maria da Penha. Uma das principais hipóteses que levam os casos de violência doméstica à impunidade é a possiblidade de retratação da vítima nos crimes em que são permitidos tais institutos, como é o caso do delito de ameaça. Outra hipótese é a morosidade na tramitação dos processos. Sob o prisma metodológico, esse trabalho fez uso do modelo de fluxo para avaliar o funcionamento do sistema da justiça criminal para o crime de ameaça cometido no âmbito doméstico, sob uma análise longitudinal prospectiva. Após a coleta de dados e representação gráfica dos resultados obtidos, concluiu-se que a desistência da vítima em processar o agressor representa um óbice ao jus puniendi do Estado ao retirar do Poder Judiciário a possiblidade de prestar um serviço jurisdicional compatível com a agressão sofrida, tornando-se um verdadeiro círculo de violência.
\end{abstract}

Palavras-chave: Estudos de fluxos. Sistema de Justiça Criminal. Violência doméstica. Crime de Ameaça. Impunidade.

\footnotetext{
${ }^{75}$ Mestrando em Direito pela Universidade Federal do Rio Grande do Norte - UFRN. Especialista em Ciências Criminais e Segurança Pública pela Faculdade Integrada de Patos/PB - FIP. Bacharel em Direito pela Universidade Federal de Campina Grande - UFCG.

${ }^{76}$ Doutora em Recursos Naturais pela Universidade Federal de Campina Grande - UFCG. Mestre em Direito pela Universidade Federal do Rio Grande do Norte - UFRN. Bacharel em Direito pela Universidade Estadual da Paraíba - UEPB. Tecnóloga em Processamento de Dados pela Universidade Federal da Paraíba - UFPB. Mestre pelo Programa Interdisciplinar em Ciências da Sociedade, na área de Políticas Sociais, Conflito e Regulação Social, pela UEPB. É Advogada e Professora na graduação e pós-graduação da UFRN.

77 Pós-doutor pelo Instituto de Direito Internacional Privado e Direito Comparado da Universität Osnabrück/Alemanha. Doutor e Mestre em Direito pela Universität Osnabrück/Alemanha. Graduado em Direito pela Universidade Federal da Paraíba - UFPB. Professor Titular da Universidade Federal do Rio Grande do Norte - UFRN.
} 


\section{INTRODUÇÃO}

A violência doméstica é, na sua essência, uma prática que remonta aos primórdios da estruturação da sociedade, que é de ordem patriarcalista e a vê como instrumento de disciplina da figura feminina e consolida a supremacia institucional do homem, o que acarretava - e ainda acarreta - a submissão da figura da mulher e o seu confinamento ao espaço do lar, podando-lhe a autonomia necessária para dividir democraticamente o espaço social com o sexo masculino, que acaba, dessa forma, sendo "único" capaz de exercer os atos da vida pública de forma emancipada (COSTA, BONFIGLIO, ROSA \& ALMEIDA, 2013, p. 01).

Segundo Kate Millett, é o patriarcado a instituição que operacionaliza a divisão sexista fornecendo os princípios e valores que organizam a sociedade com base em diferenças hierarquizadas e afirma que o "patriarcado é uma ideologia dominante que não admite rival; talvez nenhum outro sistema tenha exercido um controle tão completo sobre seus súditos" (1975 apud SILVA, 2008, p. 08).

A tradição patriarcal denota essa submissão da mulher ao homem, fruto de um processo histórico de centralização da figura masculina nas relações sociais. Nesse modelo de sociedade patriarcal, ainda preponderante nos dias atuais, as mulheres enfrentam uma espécie de relação de dependência estrutural do homem, seja ela afetiva e/ou financeira, tornando o processo de denunciação do agressor muito complexo e dificultoso para a vítima.

Em outras palavras, nos crimes cometidos no âmbito doméstico, pelas circunstâncias de intimidade em que ocorrem, ainda é muito difícil para vítima denunciar o agressor, o qual, na maioria das vezes, mantém com ela uma relação de convivência diária. Nesse esteio, a violência doméstica é silenciosa porque as mulheres, ou por medo ou por vergonha, não revelam tudo que se passa (ROCHA, 2010), dificultando o processo de reconhecimento e punição de seus agressores.

Da forma como está socializada, a violência contra a mulher nem sempre é percebida, tornando-se muitas vezes invisível. Ela ocorre, principalmente, em relações privadas entre os membros da mesma família e tem o domicílio como o espaço físico onde frequentemente se manifesta, por isso denominada de violência doméstica (MEDEIROS, 2004, p. 07).

A Organização Mundial da Saúde, em seus estudos, indica que quase a metade das mulheres vítimas de homicídio são assassinadas pelo marido ou namorado, tanto pelo excompanheiro, como também pelo atual. Da mesma forma, pesquisa realizada pela Anistia Internacional em cinquenta países trouxe dados que revelaram que uma em cada três mulheres 
foi vítima de violência doméstica, como também obrigada a manter relações sexuais ou submetida a outros tipos de violência (SABADELL, 2005, p. 258). A violência de gênero é, talvez, a mais preocupante forma de violência, porque, literalmente, a vítima, nesses casos, por absoluta falta de alternativa, é obrigada a dormir com o inimigo. É um tipo de violência que, na maioria das vezes, ocorre onde deveria ser um local de recesso e harmonia, onde deveria imperar um ambiente de respeito e afeto, que é o lar, o seio familiar (BASTOS, 2007, p. 125).

A violência doméstica é, portanto, definida a partir de um aspecto contextual, considerando que ocorre entre membros interligados por uma relação familiar, que compartilham o mesmo ambiente, não delimitado aqui apenas as extensões físicas.

Visando coibir esses atos de violência contra a mulher, foi editada em 2006 a Lei n. ${ }^{\circ}$ 11.340, conhecida por Lei Maria da Penha (LMP), composta por dispositivos legais que conferem mais rigor às punições sobre crimes domésticos (BRASIL, 2006), tornando-se a política pública mais importante do Brasil nos últimos anos, no que diz respeito ao enfrentamento e repressão dessa espécie de violência.

A Lei Maria da Penha constituiu um marco histórico na democracia brasileira, sendo resultado dos esforços do movimento feminista78 e dos movimentos sociais pela efetivação dos direitos humanos, significando a concretização de um instrumento legal de combate à violência contra a mulher, tendo sido elaborada através de um demorado processo de discussões e audiências públicas, com a presença de inúmeros segmentos sociais (LIMA, SOUSA \& SOUZA, 2010, p. 03).

Contudo, em que pesem tais avanços, a LMP ainda deixa muito a desejar quando se fala em punição, em criminalização dos sujeitos que cometem os delitos definidos pela lei. Por serem considerados delitos de proximidade, na medida em que ocorrem entre pessoas que possuem algum tipo de vínculo afetivo, os envolvidos possuem grande dificuldade em administrá-los e levá-los a conhecimento da autoridade policial.

Nessa perspectiva, percebe-se que uma das principais hipóteses que levam os casos de violência doméstica à impunidade é, provavelmente, a possiblidade de retratação da vítima, seja pela não representação ou pela renúncia ao direito de processar o ofensor, nos crimes em

\footnotetext{
${ }^{78}$ O Feminismo surge e se organiza como movimento estruturado, a partir do fenômeno da modernidade, acompanhando o percurso de sua evolução desde o século XVIII, tomando corpo no século XIX, na Europa e nos Estados Unidos, transformando-se, também, em instrumento de críticas da sociedade moderna. E, apesar da diversidade de sua atuação, tanto nos aspectos teóricos, quanto nos aspectos práticos, o Feminismo vem conservando uma de suas principais características que é a reflexão crítica sobre as contradições da modernidade, principalmente, no que tange a libertação das mulheres (SILVA, 2008, p.1-2).
} 
que são permitidos tais institutos, ou mesmo sua desistência em prosseguir com a notitia criminis levada a efeito perante a autoridade policial, como é o caso do crime de ameaça.

Nesse prisma, a renúncia por parte da vítima se mostra como obstáculo à efetivação da LMP. Associada a outras causas, como a morosidade na tramitação dos processos, tais fatores apresentam-se como gargalos diante o Sistema de Justiça Criminal no que diz respeito ao processamento eficiente desses delitos, acarretando uma sensação da impunidade por parte da população. Esses são alguns dos fatores (gargalos) que podem estar presentes no fluxo no sistema de justiça criminal dos crimes domésticos, e é sobre eles que esta pesquisa pretende se debruçar.

Visando alcançar o objetivo proposto, esse trabalho considerará, sob o prisma metodológico, o modelo de fluxo79 para avaliar o funcionamento do sistema da justiça criminal para o crime de ameaça cometido no âmbito doméstico, sob uma análise longitudinal prospectiva, analisando a tramitação dos processos iniciados e quais deles alcançaram a fase de sentença.

Em outras palavras, esta pesquisa se dará pelo mapeamento de processos que envolvam casos de violência doméstica, especificamente no que diz respeito ao delito de ameaça, tipificado no art. 147, do CP, iniciados perante o Poder Judiciário (Juizado da Violência Doméstica e Familiar Contra a Mulher), e, dentre eles, quais obtiveram sentença e/ou quais foram arquivados/extintos. Para tanto, será realizada uma pesquisa documental, explicativa dos fatores de impunidade e de morosidade no tratamento do crime em questão.

A impunidade, nesta pesquisa, será aferida a partir da relação (razão) existente entre os processos iniciados perante o Juizado da Violência Doméstica e Familiar Contra a Mulher e quais alcançaram a fase de sentença (efeito funil); pelo tempo de duração dos processos; bem como pela incidência de casos em que as vítimas, durante o andamento dos processos, renunciaram o direito de processar seus agressores.

Registre-se, por fim, que o acesso às informações se deu de forma mais rápida e menos burocrática em razão de um dos autores - Douglas da Silva Araújo - ser servidor do Tribunal de Justiça do Rio Grande do Norte e por isso já ter login e senhas dos sistemas operados durante o levantamento dos dados, o que facilitou a dedução e ilações sobre o material coletado por todos os autores.

\footnotetext{
${ }^{79} \mathrm{O}$ estudo do fluxo da Justiça Criminal é um poderoso instrumento de reflexão sobre acesso diferencial à Justiça e é ainda pouco explorado no Brasil. Embora tenhamos um crescente número de estudos nos últimos anos, ainda são poucos os estudos que procuram identificar e investigar os processos de filtragem dos envolvidos nos crimes (VARGAS, J.D e RIBEIRO, L.M.L. 2008. "Estudos de Fluxo da Justiça Criminal: Balanço e Perspectivas". $32^{\circ}$ Encontro Anual da ANPOCS. Caxambu, MG, 2008).
} 


\section{SISTEMA DE JUSTIÇA CRIMINAL E VIOLÊNCIA DOMÉSTICA CONTRA AS MULHERES}

Por sistema de justiça criminal, entende-se a articulação entre as organizações policiais (em regra, Polícia Militar e Polícia Civil), o Ministério Público, a Defensoria Pública, o Poder Judiciário e o sistema Penitenciário com o objetivo de viabilizar o processamento dos conflitos classificados como delitos (crimes ou contravenções) nas leis penais brasileiras (RIBEIRO \& SILVA, 2010).

Os índices resultantes da análise do processamento de crimes nas instâncias acima elencadas podem ser demonstrados por meio de fluxos. Os estudos sobre fluxo do âmbito da justiça criminal, em crescente ascensão no Brasil, preocupam-se, na sua generalidade, em analisar a eficiência do sistema criminal no que diz respeito ao processamento de delitos.

Nesse contexto, a eficiência deve ser entendida como a capacidade do sistema de justiça criminal de processar e punir todos os crimes levados ao conhecimento da autoridade policial, através de uma relação entre o número de boletins de ocorrências de determinado crime e o número de sentenças condenatórias possivelmente prolatadas (COSTA, 2015).

Para fins metodológicos deste estudo, os processos serão analisados a partir de sua iniciação perante o Juizado competente até a fase de prolação da sentença. Assim, esse estudo fará uso do método de abordagem longitudinal prospectiva80, o qual será considerado a partir do mapeamento de casos tipificados pelo art. 147 do Código Penal (crime de ameaça), e enquadrados pela Lei n. ${ }^{\circ}$ 11.340/2006, que foram distribuídos perante o Juizado da Violência Doméstica e Familiar Contra a Mulher e quais deles alcançaram a fase de sentença, seja ela de condenação, absolvição ou extinção.

Como afirmado acima, o estudo de fluxo do SJC demanda o levantamento de informações a fim de promover uma construção de dados que refletem o caminho que determinada modalidade de delito percorreu desde sua comunicação à autoridade policial até o efetivo julgamento pelo Poder Judiciário (ou outro intervalo a ser considerado) e, se for o

\footnotetext{
${ }^{80}$ No método de abordagem longitudinal prospetiva o acompanhamento tem por objetivo verificar o percentual de casos que progridem para as fases subsequentes e ainda os que são arquivados antes do previsto. Trata-se de uma abordagem que permite analisar o tempo de processamento, a dinâmica das operações realizadas pelos operadores do direito, as características dos casos, das vítimas e acusados, redundando num rico material sobre as práticas judiciais e a produção de justiça. Assim, pode-se estudar a entrada e saída dos casos no sistema, bem como os resultados do processo e, por essa via, discutir o acesso diferencial à Justiça. A dimensão temporal no estudo do fluxo de justiça é, portanto, um elemento central (RIFIOTIS et al 2010).
} 
caso, até o cumprimento de pena pelo condenado no âmbito do sistema penitenciário ou de outra pena alternativa que lhe tenha sido imposta.

Nesse ínterim, este estudo pretende identificar quais fatores são preponderantes para aferir os níveis de impunidade em relação ao crime de ameaça cometido no âmbito doméstico, a partir do mapeamento de dados produzidos no âmbito do Juizado da Violência Doméstica e Familiar Contra a Mulher, instância que compõe o sistema de justiça criminal.

Quanto à definição a violência doméstica a mesma pode ser tomada como forma de constrangimento físico ou moral para alcançar fim ilícito, imoral ou não desejado pela pessoa que sofre violência, podendo até assumir a forma de coação (LIMA FILHO, 2011), configurando uma grave violação aos direitos humanos. Nesse contexto, a violência doméstica refere-se a todas as formas e comportamentos dominantes praticados no âmbito familiar, seja física, psicológica ou sexual.

$\mathrm{O}$ artigo $7^{\circ}$, da LMP, veio tratar das formas de manifestações de violência doméstica e familiar, não apenas da violência de natureza física, sexual ou psicológica, comumente mais conhecidas, mas abrangendo outras espécies da violência, como a patrimonial e a moral.

Para a doutrina jurídica penal, a violência física é todo tipo de lesão à integridade e saúde corporal. Em outros dizeres, violência física é o uso da força, mediante socos, tapas, pontapés, empurrões, arremessos de objetos, queimaduras etc., visando, desse modo, ofender a integridade ou a saúde corporal da vítima, deixando ou não marcas aparentes, naquilo que se denomina tradicionalmente, vis corporalis. São condutas previstas, por exemplo, no Código Penal, configurando os crimes de lesão corporal e homicídio e mesmo na Lei das Contravenções Penais, como a via de fato (CUNHA \& PINTO, 2013). Já a lesão psicológica se configura pela experimentação por parte da vítima de agressões verbais, ou pressão emocional, imposição da prática de ato que causa ultraje à vítima, submetê-la à prática de atos sexuais degradantes a sua condição e prática de atos fraudulentos que fira seu patrimônio (PARODI \& GAMA, 2012). A violência sexual, para a LMP, é entendida como qualquer ato que constranja ou coaja alguém a participar ou praticar ato sexual, com o uso da força ou ameaça. Vai ainda mais além de apenas atos sexuais, compreendendo nesse tipo de violência a oposição de olhar imagens pornográficas, o impedimento de utilização de métodos contraceptivos, o matrimônio forçado ou a imposição de aborto. Por seu turno, a violência patrimonial, disposta no inciso IV, é entendida como qualquer conduta cometida no âmbito doméstico e familiar em desfavor da mulher e configuradora de retenção (posse de coisa da mulher garantindo direito próprio), de subtração (retirada, ocultamento, e não podendo cogitar o furto, em razão do estabelecido no artigo 181 do Código Penal), de destruição parcial ou 
total de objetos, instrumentos de trabalho, documentos pessoais, bens, valores e direitos ou recursos econômicos, incluindo os destinados a satisfazer as necessidades pessoais (FILHO, 2011). Por fim, a violência moral é qualquer ato verbal que agrave a imagem da mulher. A violência verbal, ou seja, calúnia, difamação ou injúria normalmente se dão concomitantemente com a violência psicológica (CUNHA \& PINTO, 2013).

Em relação ao tipo de ação penal correspondente aos crimes domésticos definidos pela Lei 11.360/06, é sabido que no julgamento da ADI 4424 DF o STF firmou a orientação de que a natureza da ação do crime de lesões corporais, praticadas no âmbito doméstico, é sempre a pública incondicionada, sem possibilidade de retratação da vítima, não importando em que extensão (leve, grave ou gravíssima, dolosa ou culposa), o que fez o STJ rever sua jurisprudência e passar a acompanhar o entendimento do STF sobre a matéria, publicando então a Súmula 542: “A ação penal relativa ao crime de lesão corporal resultante de violência doméstica contra a mulher é pública incondicionada”. Nesse novo entendimento, é possível, por exemplo, que uma notícia-crime seja dada por um vizinho, um familiar que hajam percebido/presenciado a violência.

Considerando a natureza incondicionada da ação para o crime de lesão corporal, o inquérito policial será instaurado para que se apure o fato e o Ministério Público, se for o caso, pode dar início à ação penal, sendo irrelevante a representação da vítima ou a sua posterior retratação.

Entretanto, mesmo no âmbito da Lei 11360/06, outros crimes ainda comportam o referido instituto, sobretudo os que se processam por meio de ação penal pública condicionada a representação da vítima ou por meio de ação penal privada, como é caso dos crimes contra a honra (calúnia, difamação e injúria), o crime de ameaça, o crime de dano, dentre outros. E nesses casos, a renúncia ao direito de processar pode obstar o julgamento dos delitos, impedindo uma punição efetiva por parte da Justiça. Portanto, o artigo 16 da LMP continua eficaz em relação a todos os crimes onde o Código Penal e legislação esparsa exija a representação como condição de procedibilidade.

Importante destacar que a renúncia à representação será admitida até o recebimento da denúncia pelo Juiz, devendo ser realizada a audiência para tanto. Observe-se a formalidade que guarnece o exercício do instituto que, apesar de ser ato informal, o legislador exigiu ratificação da vontade negativa perante o juiz, em audiência especialmente designada para essa finalidade (art. 16 da Lei 11.360/06).

Registre-se, a título aclaratório, que o artigo 16 da LMP contém impropriedade técnica em sua dicção ao mencionar "renúncia" quando, na verdade, está se tratando de "retratação". 
A par dessa discussão, percebe-se que a Lei 11.360/06 representou uma evolução jurídica em relação à proteção da mulher, reconhecendo sua hipossuficiência nas relações sociais e fornecendo-lhe garantias que a coloque em posição de igualdade com o homem. Porém, em que pese o avanço legislativo, consubstanciado em política pública de combate a criminalidade quando a mulher é vítima de delito, nota-se uma baixa capacidade de punição por parte da justiça criminal brasileira nesses casos.

\section{O FLUXO DO CRIME DE AMEAÇA NO ÂMBITO DO $2^{\circ}$ JUIZADO DA VIOLÊNCIA DOMÉSTICA E FAMILIAR CONTRA MULHER: APLICAÇÃO DE QUESTIONÁRIO E RESULTADOS DA PESQUISA}

O crime de ameaça encontra-se previsto no artigo 147 do Código Penal, que se encontra incluído na Seção I - Dos crimes contra a liberdade pessoal, compreendido entre os crimes contra a liberdade individual (capítulo VI), e consiste no ato de "ameaçar alguém, por palavra, escrito ou gesto, ou qualquer outro meio simbólico, de causar-lhe mal injusto e grave".

Maria Helena Diniz (1988, p. 188) aduz que o crime de ameaça "na linguagem comum, designa a perspectiva de um mal, que vem a abolir ou a restringir a livre manifestação da vontade de alguém, atemorizando-o, enunciada por palavra, gesto ou sinal [...] promessa de fazer um mal injusto e grave a outrem, incutindo lhe sério receio".

A consumação do crime de ameaça, segundo Damásio de Jesus (1999, p. 473), ocorre quando "o sujeito passivo toma conhecimento do mal pronunciado, independente de sentir-se ameaçado ou não".

A ameaça, portanto, causa uma constrição na liberdade de autodeterminação do sujeito, de modo que o temor provocado pelo crime causa perturbação psíquica, sendo objeto de tutela pelo direito penal.

Ao sujeito que comete o crime de ameaça, no âmbito doméstico e familiar contra a mulher, mesmo se tratando de um crime de menor potencial ofensivo, diante da vedação trazida no art. 41 da Lei n. ${ }^{\circ}$ 11.340/2006 (Lei Maria da Penha), não é possível a concessão dos benefícios da composição civil, da transação penal e da suspensão condicional do processo.

No que se refere ao tipo de ação penal, mesmo no âmbito da Lei Maria da Penha, o crime de ameaça continua como sendo de ação pública condicionada à representação da 
ofendida. Contudo, por força normativa do art. 16 da Lei 11.340 /2006, a desistência da vítima reveste-se de maiores formalidades, sendo necessária a realização de audiência para sua oitiva, oportunidade na qual poderá abdicar de processar o acusado.

Nesse diapasão, os crimes cometidos sob a égide da Lei Maria da Penha gozam de trâmite processual com características peculiares, como é o caso da mencionada audiência prevista no art. 16 da norma, que será mais bem detalhado a seguir, a partir da pesquisa desenvolvida em juizado de violência doméstica da cidade de Natal, capital do no Rio Grande do Norte.

O $2^{\circ}$ Juizado de Violência Doméstica e Familiar contra a Mulher da Comarca de Natal/RN foi criado pela Resolução n. ${ }^{o}$ 12/201581, de 29 de julho de 2015 que alterou a Lei de Organização Judiciária do Estado do Rio Grande do Norte (Lei Complementar n. ${ }^{\circ}$ 165, de 28 de abril de 1999).

O respectivo juizado tem competência para processar e julgar as causas enquadradas pela Lei n. ${ }^{\circ}$ 11.340/2006, a conhecida Lei Maria da Penha, sejam eles medidas protetivas, ações penais, termos circunstanciados, boletins de ocorrências, procedimentos cíveis originados dos casos de violência domésticos, dentre outros.

Por ser muito recente, considerando que sua criação data de julho de 2015, o referido juízo ainda conta com muitos dos procedimentos inconclusos. Porém, a escolha do locus desta pesquisa se deu em razão de um dos autores ser servidor público do Tribunal de Justiça do Rio Grande do Norte e, por isso, ter tido acesso facilitado ao acervo processual após autorização da Magistrada Titular do Juizado de Violência Doméstica, a Juíza Rossana Maria de Andrade Paiva.

Tendo em vista o grande número de processos em tramitação no respectivo órgão jurisdicional, buscou-se inicialmente estabelecer o lapso temporal a ser considerado no levantamento de dados. Por ser um juizado de origem recente, selecionou-se o período compreendido entre 01 de janeiro de 2016 a 30 de junho de 2016, ou seja, o primeiro semestre do ano em questão.

\footnotetext{
${ }^{81}$ Com a entrada em vigor da Resolução no 12/2015-TJ, de 29.07.2015, a $2^{\text {a }}$ Vara de Sucessões da Comarca de Natal foi transformada no $2^{\text {a }}$ Juizado de Violência Doméstica, e o Juizado de Violência Doméstica existente foi renomeado para $1^{\circ}$ Juizado de Violência Doméstica e Familiar Contra a Mulher da Comarca de Natal, conforme se vê a seguir:

Art. $1^{\circ}$ Fica transformada a $2^{a}$ Vara de Sucessões da Comarca de Natal no $2^{\circ}$ Juizado de Violência Doméstica e Familiar contra a Mulher da Comarca de Natal, com competência, por distribuição, para processar e julgar as causas a que se refere a Lei $n^{\circ} 11.340$, de 7 de agosto de 2006.

Art. $2^{\circ}$ Renomear o atual Juizado de Violência Doméstica e Familiar contra a Mulher da Comarca de Natal para

$1^{\circ}$ Juizado de Violência Doméstica e Familiar contra a Mulher da Comarca de Natal.
} 
Serão analisados, dessa forma, os processos em trâmite no $2^{\circ}$ Juizado de Violência Doméstico que tratem do crime de ameaça, distribuídos no período de janeiro a junho de 2016. Distribuídos aqui é sinônimo de iniciados, referindo-se aos processos que deram entrada no juizado nesse tempo, o que não quer dizer necessariamente que os crimes foram cometidos nesse período, mas sim que os procedimentos (inquérito policial/termo circunstanciado) findaram na Delegacia Especializada e foram remetidos ao Juizado competente.

No período considerado (até junho de 2016) existiam 3.279 processos/procedimentos (incluídos os inquéritos policiais) em “andamento" no $2^{\circ}$ Juizado de Violência Doméstica da Comarca de Natal, alguns já finalizados (sentenciados), outros ainda em trâmite.

É importante ressaltar que o juizado faz uso do sistema SAJ (Sistema de Automação Judicial), uma ferramenta desenvolvida para facilitar a automatização das rotinas jurisdicionais e administrativas, fazendo uso de tecnologias que visam à implantação do processo digital, garantindo e viabilizando ganhos de produtividade e otimização dos recursos pelos Tribunais de Justiça, Ministérios Público e Procuradorias estaduais e municipais82.

Todos os números até então descritos, seja do acervo total dos processos do juizado, seja dos processos considerados para este estudo, foram extraídos por meio do sistema SAJ, na aba "Consulta" e na opção "Relatório Analítico de Distribuição", tendo sido necessário fornecer alguns parâmetros de pesquisa para obter a numeração correspondente ao período desejado.

Por exemplo, visando conseguir os processos que cuidam do crime de ameaça, selecionou-se o período desejado, isto é, os processos em tramitação no período de 01 de janeiro de 2016 a 30 de junho de 2016. Após, foi informado a classe processual desejada. Como o período é bastante recente (janeiro/junho de 2016), bem como o próprio juizado foi criado a pouco mais de dois anos, selecionou-se as ações penais e os inquéritos policiais que foram distribuídos/redistribuídos no período em análise. Registre-se aqui que foram dispensados os processos referentes às medidas protetivas, porquanto na sua maioria referemse a casos que já foram instaurados inquéritos policiais e que, portanto, poderiam resultar na duplicidade de análises, isto é, o processo de medida protetiva poderia ser o mesmo caso já investigado por meio de inquérito policial, ambos em curso perante o Juizado de Violência Doméstica. Foram dispensados também os procedimentos menos formais, como os termos circunstanciados, que na sua maior parte referem-se a crimes contra honra, desimportante para

\footnotetext{
${ }^{82}$ SAJ DIGITAL. Disponível em: <http://www.sajdigital.com.br/o-saj/>. Acesso em 30 jun. 2017.
} 
este trabalho. Ainda foram dispensadas as execuções penais, visto que esta pesquisa se propôs a analisar os processos incluídos no intervalo referente à distribuição/redistribuição até a fase da sentença, caso já tenha ocorrido.

Selecionada a classe processual, como dito, os inquéritos policiais e as ações penais, foi informada a competência, a saber, "Violência Doméstica Contra Mulher", depois foi escolhida a Vara/Juizado, qual seja, o "2º Juizado da Violência Doméstica e Familiar Contra a Mulher”, e ainda a área. Neste último parâmetro, existem três opções de seleção -cível criminal - ou ambas. Como se investiga processos que versam sobre o crime de ameaça selecionou-se a opção "criminal". E por último parâmetro escolheu-se o assunto, que no presente caso é o delito estudado, isto é, o crime de ameaça.

Fornecidos todos os parâmetros chegou-se ao número de 207 processos, sendo eles ações penais e inquéritos policiais. A vista desse número, ponderando se tratar de uma pesquisa de mestrado, cujo tempo da pesquisa é mais curto, bem como de um trabalho quantitativo que possivelmente oferecerá diretrizes para uma tese de doutorado futura, usouse uma amostragem do universo analisado.

Considerando um intervalo de confiança igual a 07 (sete), e nível de confiança igual a 95\% (noventa e cinco por cento), aplicado a uma população de 207 processos, chegou-se a amostra de 101 processos, representativos do período de janeiro a junho de 2016.

Fazendo uso de site especializado, realizou-se posteriormente um sorteio aleatório de 101 processos no universo de 207, o que resultou nos números dos processos a serem vislumbrados pelos autores.

A par do quantitativo de processos a serem garimpados pelo pesquisador, iniciou-se a coleta um a um e, logo após, a inserção dos dados no questionário previamente formulado. Finalizada a coleta, seguem os resultados para análise e inferências.

\subsection{Aspectos processuais: do inquérito policial ao processo judicial}

No que diz respeito à existência de prisão em flagrante ou não do acusado nos processos referentes ao crime de ameaça, percebe-se que quase a totalidade de comunicação dos casos é feitas por meio de registro de boletim de ocorrência (99\%), ou seja, é mais raro o flagrante nesses casos. A vítima que é responsável por noticiar o delito à autoridade policial. Uma possível explicação para isso seria o caso do crime em questão tratar-se de um delito de proximidade. Nesses crimes os envolvidos possuem, geralmente, grande dificuldade em administrá-los, pois são resultantes de um contexto de discórdia e costumam ocorrer em locais 
que proporcionam algum grau de intimidade entre as partes envolvidas, como espaços domésticos, locais de vizinhança, espaços de trabalho, de lazer (VASCONCELLOS, 2014). Os crimes de proximidade são de dificultosos inclusive para atuação da polícia, ante sua imprevisibilidade, e as circunstâncias de intimidade e espacialidade que lhe caracterizam.

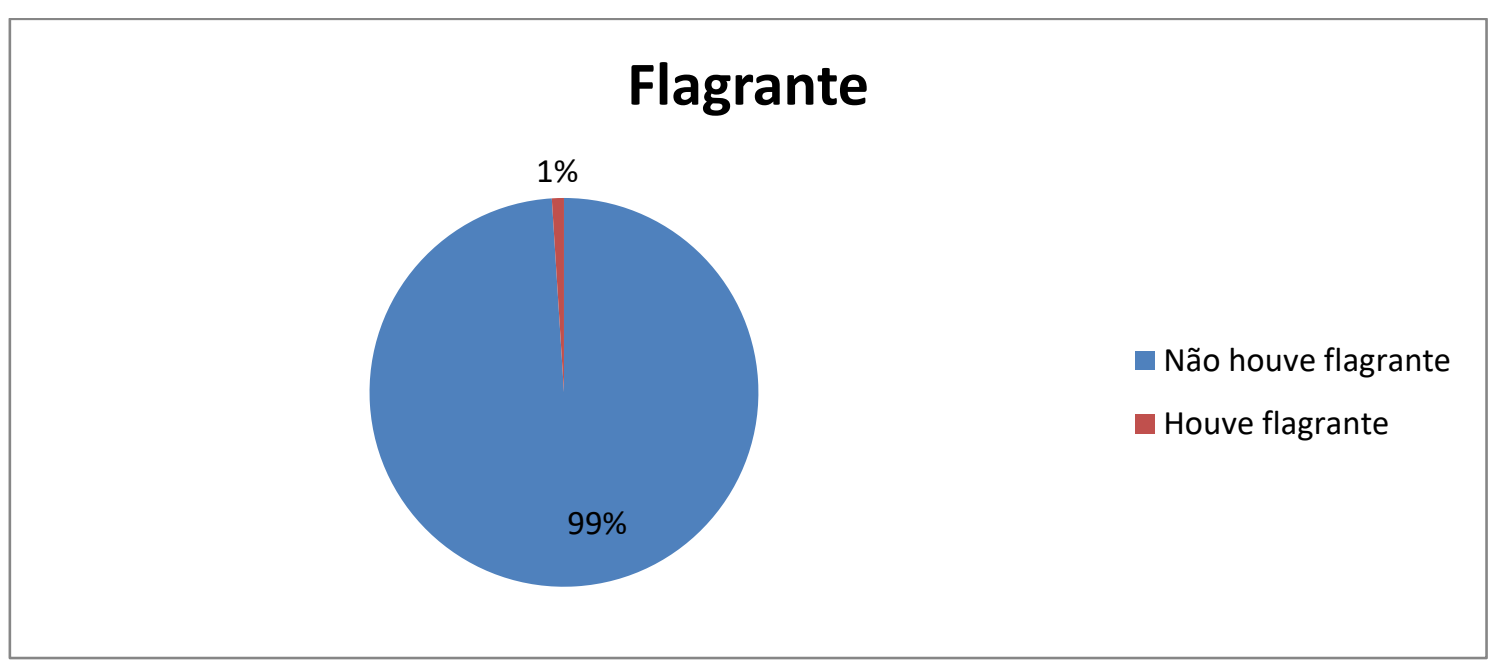

Fonte: Elaborado pelos autores, 2018.

No que diz respeito à existência de medidas protetivas nos casos investigados, verifica-se que em $81,2 \%$ (82 casos) foram requisitadas e deferidas medidas pelo Juízo competente, demonstrando que esse instituto funciona como uma espécie de "resposta rápida" por parte do Poder Judiciário a fim de resguardar o bem jurídico agredido, molestado, isto é, a própria vítima. Nesse primeiro momento, busca-se proteger a integridade física, moral, psicológica e/ou patrimonial da vítima que acabara de ser violentada.

A finalidade das medidas protetivas é assegurar direitos fundamentais, evitando a continuidade da violência e das situações que a favorecem, não representando, necessariamente, medidas preparatórias de qualquer ação judicial. Elas não visam processos, mas pessoas (LIMA, 2011, p. 329).

Nessa perspectiva, as medidas protetivas funcionam como limites para o agressor e criam certa rede de proteção para as mulheres que ficam livres do assédio e da ameaça constantes, que assim podem ter alguma tranquilidade para refletir sobre os encaminhamentos que poderão buscar para sair da situação de violência (PASINATO, 2015, p. 417). 


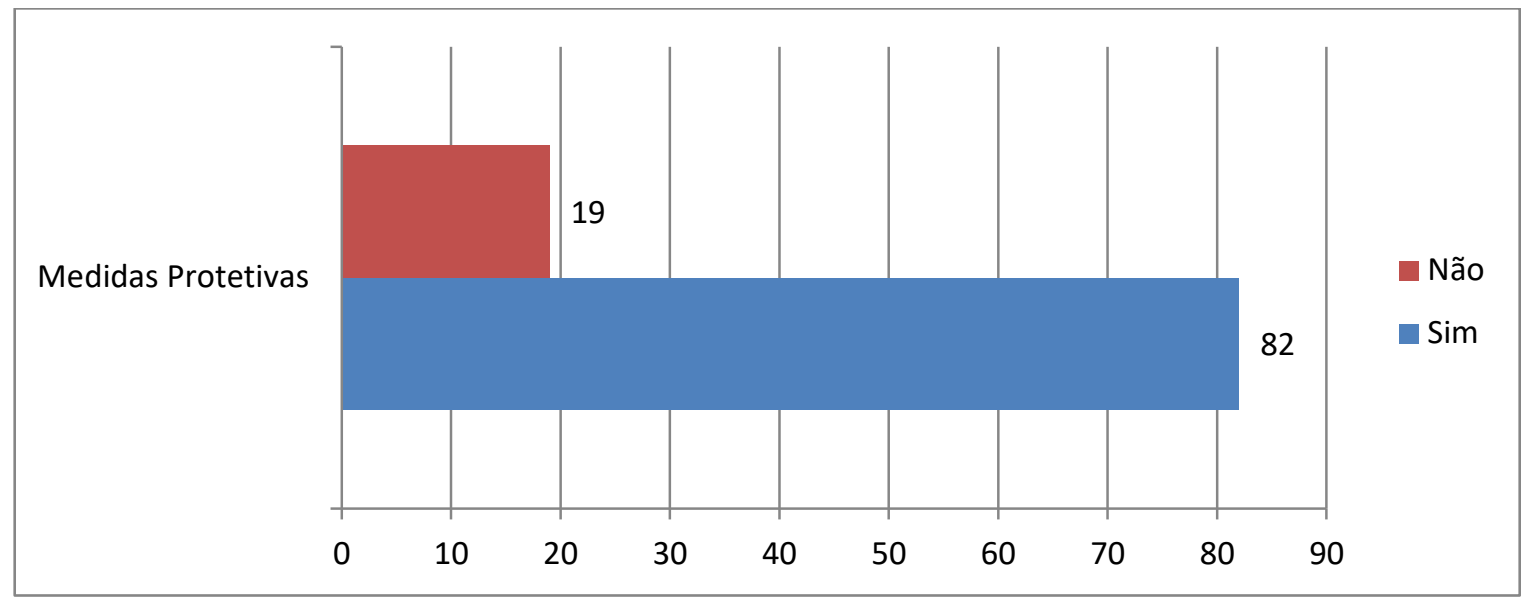

Fonte: Elaborado pelos autores, 2018.

Quanto à indagação da ocorrência do delito de ameaça isoladamente ou conjunto com outro delito, vislumbra-se que, comumente (cerca de 50\% dos casos), o crime vem acompanhado de outra espécie delituosa, seja de lesão corporal, constrangimento ilegal, violação de domicílio, crimes contra a honra, vias de fato, dentre outros. Pode-se afirmar que a ameaça é uma espécie de crime que costuma acompanhar outro delito.

De acordo com o Dossiê Mulher de 2016 (2016:18) a ameaça, que está relacionada à violência psicológica, contabilizou, em 2015, 4.931 vítimas registradas, com as mulheres representando 65,2\% desse total; e constrangimento ilegal, com 1.090 vítimas, sendo 637 do sexo feminino $(58,4 \%)$. Aproximadamente $60,0 \%$ dos casos de violência psicológica contra mulheres estão relacionados à violência doméstica e/ou familiar. Os casos que envolvem o crime de ameaça são geralmente acompanhados de outras formas de violência praticadas num mesmo evento.

\section{Crime constante no processo:}

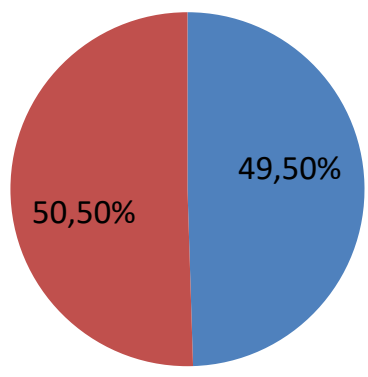

Ameaça (art. 147 do CP)

- Ameaça e outro delito

Fonte: Elaborado pelos autores, 2018. 
Quanto à condição de procedibilidade relativa à representação do ofendido, constatase que a maior parte das ofendidas $(71,3 \%)$ não renunciou a representação, isto é, não se retratou do desejo de processar seu agressor. Registre-se que este aspecto, relativo à condição de procedibilidade, foi visualizado, num primeiro momento, em sede de inquérito, ou seja, durante a instauração do procedimento investigativo pela Autoridade Policial.

Mesmo tento sido levantada a hipótese de muitas desistências por parte da vítima em dar continuidade aos processos contra os acusados, data a possibilidade de retratação que o crime comporta, verifica-se que foi observada situação diversa durante a fase policial (inquérito), ou seja, boa parte das ofendidas deu continuidade ou pelo menos não impediram dos processos avançarem até o Poder Judiciário.

Já no campo de atuação processual do Poder Judiciário, tendo por base as espécies de sentenças proferidas nos autos, verifica-se que a maioria dos processos ainda não teve sentença, certamente em razão do período considerado neste estudo ser recente. Entretanto, em segundo lugar (27,7\%), aparecem os processos arquivados. Nesses casos foram consideradas as sentenças de arquivamento quando o juiz homologa as desistências das vítimas ou os requerimentos formulados pelo Ministério Público, sob o fundamento de ausência de justa causa (prova da materialidade e indícios de autoria delitiva) para o início da ação penal.

Logo após, aparecem as sentenças de extinção, que nesta pesquisa foram consideradas aquelas que reconheceram a prescrição, a decadência, ou outra causa extintiva da punibilidade diversas daquelas que dependem de manifestação da vontade da vítima (renúncia/representação).

Finalmente e extremamente interessante, foi o fato de que em apenas dois casos houve condenação (2\%), e somente em um caso o agressor foi absolvido (1\%). Mesmo levando em consideração que os dados foram coletados de processos relativamente recentes, pode-se constatar que há uma discrepância entre o número de processos arquivados e o número de processos sentenciados, seja pela condenação ou absolvição do réu. Nesses dois últimos casos, os processos seguiram seu curso regular, com o recebimento da denúncia, a instrução processual e a consequente prolação da sentença, diversamente do que aconteceu com o primeiro caso, que o processo foi arquivado sem cumprir essas etapas.

\subsection{Aspecto temporal: duração dos processos}


Dos dados coletados dos 101 processos em trâmite no $2^{\circ}$ Juizado da Violência Doméstica e Familiar Contra a Mulher da Comarca de Natal/RN, amostra considerada para o período de janeiro a junho de 2016, verifica-se que os meses que se concentra com mais intensidade a ocorrência dos fatos é de novembro de 2015, com 12 crimes; março de 2016, com 09 crimes; e janeiro de 2016, com 08 crimes. Esses três meses totalizam 29 casos, considerando que cada processo faz referência a uma data de ocorrência do crime de ameaça. Sendo assim, quase um terço dos crimes se concentrou nos meses de novembro de 2015 e janeiro e março de 2016.

Paralelamente a esses números, na coleta referente à data da comunicação do delito à Polícia, seja através da informação fornecida pela própria vítima com a confecção do boletim de ocorrência, seja através de flagrante por parte da autoridade policial, os meses que mais se concentraram essas denúncias foram novembro de 2015, com 13 casos; janeiro de 2016, com 09 casos; março de 2016, com 08 casos, igualando-se este último ao mês de outubro do ano de 2015.

Pelas deposições acima, há uma similitude entre os meses que mais ocorreram os fatos criminosos e os meses em que houve mais comunicação à autoridade policial. É provável, que essas vítimas comunicaram de imediato ou com poucos dias do acontecimento do crime a ocorrência delituosa a polícia. E essa constatação se corrobora com a observação dos boletins de ocorrência, especialmente no que diz respeito a data do fato e a data da comunicação.

Como já afirmado, em razão do período considerado ser muito recente, não se visualizou um número considerável de sentença de condenação e absolvição. Em apenas dois casos houve condenação (2\%), e somente em um caso o agressor foi absolvido (1\%).

Entretanto, houve um número percebível de sentença nos meses de setembro (10 sentenças), outubro (04 sentenças) e dezembro (03 sentenças) de 2016. Dentre essas 17 sentenças, uma delas foi de condenação, a relativa ao processo de número 010512364.2014.8.20.0001, proferida em 26/10/2016. As demais sentenças foram de arquivamento ou extinção, isso porque, em razão da pouca quantidade, se anotou os números das sentenças de condenação e absolvição.

As sentenças do mês de setembro de 2016, de maior número, foram de arquivamento, conforme informação prestada pela Chefa de Secretaria do $2^{\circ}$ Juizado de Violência Doméstica. No referido mês realizou-se um "pautão" de audiências do art. 16 da LMP, isto é, para aqueles casos que a vítima não pretende dar prosseguimento a ação contra o acusado.

Percebe-se que das sentenças emanadas do respetivo órgão jurisdicional, mesmo que necessariamente não corresponda aos processos mapeados neste estudo, quase a totalidade 
delas foram de arquivamento em razão da desistência da vítima em processar seu agressor. Essa constatação, em certa medida, alinha-se a hipótese inicial deste trabalho.

Nessa perspectiva, pondera-se que as vítimas de conflitos domésticos não querem efetivamente processar e punir o seu agressor, querem, geralmente, interromper uma situação de violência que se perdura, ou seja, desejam apenas romper um ciclo de violência e restabelecer o pacto familiar e a paz no lar. Até mesmo as poucas mulheres que desejam a separação, no caso de violência conjugal, não almejam a persecução penal do agressor; elas preferem que a coesão familiar seja mantida, especialmente quando há filhos envolvidos. Logo, as vítimas se utilizam da ameaça de uma condenação no intuito de fazer cessar a violência (PASINATO, 2008, p. 347-348).

As vítimas buscam uma solução imediatista que, ao mesmo tempo, consiga cessar o ciclo de violência vivenciado, numa espécie de "lição" para o agressor, sem, contudo, desejar uma punição de forma mais severa, por exemplo, uma condenação advinda do Poder Judiciário.

Esse comportamento foi observado nas Delegacias Especializadas de atendimento à Mulher (DEAMs), onde as mulheres vítimas usavam do aparato da autoridade policial para coagir informalmente seu agressor, no intuito de solucionar os conflitos domésticos, distanciando-se da função de criminalização do ofensor. As vítimas registravam a ocorrência na delegacia, mas, retiravam-na após a "mediação policial”, para evitar que a Lei, impessoal, interviesse na relação privada (MORAES; SORJ, 2009, p. 15).

Mesmo após o início das ações penais, com o recebimento da denúncia por parte do Poder Judiciário, quando a vítima não poderia mais se retratar da representação criminal ou até mesmo nos casos de ações penais públicas incondicionadas, percebe um comportamento descriminalizante por parte da vítima, as quais utilizam de diversos artifícios para impedir a condenação dos seus agressores, frequentemente modificando seus depoimentos, atribuindo as lesões a acidentes e quedas e até mesmo assumindo ser responsáveis pela causação dos ferimentos (autolesões) (PASINATO, 2008, p. 348).

Nesse esteio, torna-se dificultoso para o órgão jurisdicional dar continuidade a um processo quando a principal interessada está desdizendo os fatos contados na delegacia e que, muitas vezes, não contribui de forma efetiva para o deslinde do caso e para uma possível condenação. Surge aqui um problema para o Estado que ainda é omisso nesses casos, seja pela ausência de políticas voltadas para esse fim, seja porque não fornece um aparato adequado ao acompanhamento das vítimas e de todos os envolvidos com equipe multidisciplinar, como reza a Lei Maria da Penha. Essa foi a conclusão de Alessandra 
Carneiro e Cristina Fraga, em estudo realizado com as vítimas de violência doméstica em São Borja no Rio Grande do Sul, ao entender que, apesar da Lei Maria da Penha prever "garantias" às vítimas, essas ainda são inexistentes ou não se concretizaram na prática, como, por exemplo, a atuação de uma equipe de atendimento multidisciplinar nos juizados de violência doméstica, com profissionais especializados nas áreas psicossocial, jurídica e de saúde, pronta para atender as vítimas, bem como a criação de casas-abrigos, centros de atendimento integral e multidisciplinar, delegacias e centros de saúde especializados para atender as mulheres vítimas, além de centros de educação e reabilitação para os agressores. Portanto, coibir a violência contra a mulher, utilizando-se das "garantias" previstas na Lei Maria da Penha, ainda é uma realidade bastante distante do contexto social atual (CARNEIRO \& FRAGA, 2012, p. 394-395).

Também sobre esse aspecto, porém noutra linha de pensamento, uma interessante inferência faz Barsted (2011 apud OLIVEIRA \& TAVARES, 2016, p. 92) ao aduzir que, a violência doméstica contra a mulher quando tratada como crime de menor potencial ofensivo, estimula-se a desistência das mulheres em relação ao processo judicial contra os agressores, assim como fomenta/fomentava "a ideia de impunidade presente nos costumes e na prática que leva os homens a agredirem as mulheres".

A autora fez essa referência considerando a aplicação da Lei dos Juizados Especiais aos crimes cometidos no âmbito domésticos, o que foi afastada pelo Supremo Tribunal Federal ao declarar a inconstitucionalidade do artigo 41 da Lei 11.340/2006. Porém, há certa razão na constatação disposta.

É certo que a Lei Maria da Penha estabeleceu que todo caso de violência doméstica e familiar contra a mulher deve ser considerado crime, o qual deve ser apurado mediante instauração de inquérito policial a ser remetido ao Ministério Público. É certo também que a lei enrijeceu algumas penas, como também proibiu a aplicação dos institutos despenalizadores, afastando a aplicação da Lei 9.099/95 - Lei dos Juizados Especiais. Entretanto, em alguns crimes, como é o caso da ameaça, por guardarem a essencialidade de um crime de menor potencial ofensivo, a possibilidade de desistência da vítima é ululante, não se podendo dizer que a justificativa dada por Barsted esteja superada. Com isso, também é possível fazer uma reflexão acerca do cabimento do instituto da retratação nos crimes cometidos no âmbito doméstico e familiar. 
No que refere aos casos de ameaça, distribuídos e sentenciados no $2^{\circ}$ Juizado de Violência Doméstica e Familiar contra a Mulher, no período coletado (janeiro a junho de 2016), vislumbra-se que, após exatamente um ano, muitos ainda continuam em tramitação, sem terem recebido uma sentença terminativa. Se considerados que muitos dos casos reportam ao segundo semestre do ano de 2015, já são quase dois anos de tramitação entre as instancias Delegacia Especializada, Ministério Público e Poder Judiciário. Anote-se que a criação dos Juizados de Violência Doméstica se deu com o intuito de amparar e proteger de maneira especial as ofendidas e de dar mais celeridade aos processos criminais, visando alcançar uma punição rápida e efetiva dos agressores. Ao se alongar por muito tempo, a morosidade na resolução dos processos representa um dos fatores responsáveis por promover a impunidade, se pensarmos nesse tempo como uma possibilidade da vítima repensar sobre os fatos ou, diante da pena do delito, ocorrer a prescrição da pretensão punitiva do Estado.

Observou-se que as sentenças proferidas pelo Juizado em análise foram pelo arquivamento dos processos em face da desistência da vítima em processar o agressor, o que retira do Poder Judiciário a possiblidade de prestar um serviço jurisdicional compatível com a agressão sofrida e que, consequentemente, causa um esvaimento de uma possível punição. Portanto, a possibilidade de retratação da vítima constitui um gargalo no processo de evidenciação da violência doméstica (por vezes crônica) e punição dos agressores.

$\mathrm{Na}$ maioria dos casos, as vítimas se valem da autoridade policial na busca de uma solução imediatista que consiga cessar o ciclo de violência vivenciado, e que funcione como uma espécie de "lição" para o agressor. Certamente tal constatação justifica o grande número de medidas protetivas solicitadas pelas vítimas em quase toda a maioria dos casos investigados, somando-se ao fato da existência de uma expectativa por uma "resposta" rápida por parte do Sistema de Justiça Criminal.

Entretanto, esse imediatismo se dissipou logo em seguida, seja porque em verdade a vítima deseja o restabelecimento da paz conjugal, da harmonia do ambiente familiar, seja porque lhe faltam estímulos e esclarecimentos acerca de suas garantias e direitos e, nesse ponto, concentra-se o importante papel da presença de uma equipe multidisciplinar, tanto na Delegacia de Polícia, como no Juizado, que lhe forneça o acompanhamento necessário, mediando o diálogo entre a vítima, os envolvidos e as instancias que compõe o sistema.

Tal equipe poderia ainda se voltar com mais eficiência aos grupos mais incidentes de vítimas e agressores, às zonas mais vulneráveis da cidade, conforme o levantamento aqui realizado, entalecendo redes de captação de informações e promovendo programas de 
prevenção, considerando que em muitos dos casos as vítimas adotam uma narrativa com tom de reincidência.

Com isso talvez se consiga dar mais efetividade aos programas de assistência e proteção às mulheres vítimas de violência doméstica, estatuídos pela Lei Maria da Penha, evitando que muito dos crimes saiam impunes ante a desistência das ofendidas em processar seus algozes.

\section{REFERÊNCIAS}

Lei Maria da Penha. Lei N. ${ }^{\circ} 11.340$, de 07 de Agosto de 2006.

ALMEIDA, Laís de. Violência Juvenil: a família no banco dos réus. Trinolex.com, Franca. Ano 1. N.6; 2007.

BASTOS, Marcelo Lessa. Violência Doméstica e Familiar contra a Mulher - Lei "Maria da Penha" - Alguns comentários. IN: FREITAS, André Guilherme Tavares de (org.). Novas Leis de Violência Doméstica contra a Mulher e de Tóxicos (Lei 11.340/06 e 11.343/06) Doutrina e Legislação. Rio de Janeiro: Editora Lumen Juris, 2007.

BRASIL. Conselho Nacional de Justiça (CNJ). CNJ Serviço: passo a passo do processo de violência contra a mulher. Disponível em: http://www.cnj.jus.br/noticias/cnj/83023-cnjservico-passo-a-passo-do-processo-de-violencia-contra-a-mulher>. Acesso em 01 jul. 2017.

CANO, I.; DUARTE, T. Mensurando a impunidade no sistema de justiça criminal do Rio de Janeiro. In: Segurança, Justiça e Cidadania, vol. 4, p. 10-43, 2010.

CARNEIRO, Alessandra Acosta; FRAGA, Cristina Kologeski. A Lei Maria da Penha e a proteção legal à mulher vítima em São Borja no Rio Grande do Sul: da violência denunciada à violência silenciada. Serv. Soc. Soc., São Paulo, n. 110, p. 369-397, abr./jun. 2012.

COELHO, Edmundo Campos. 1986. A administração da Justiça Criminal no Rio de Janeiro: 1942-1967. Dados - Revista de Ciências Sociais, Rio de Janeiro, Iuperj, v. 29, n. 1, pp. 61-81.

COSTA, Arthur Trindade M. A (in)efetividade da justiça criminal brasileira: Uma análise do fluxo de justiça dos homicídios no Distrito Federal. Civitas: Revista de Ciências Sociais, v. 15, n. 1, p.11-26, 2015. 
COSTA, Érica Oliveira; BONFIGLIO, Luiza Pinheiro; ROSA, Victória Lange da; ALMEIDA, Bruno Rotta (Orientador). O atual cenário da violência doméstica no Brasil. In: $22^{\circ}$ Congresso de Iniciação Científica. Pelotas/RS: UFPel, 2013. Disponível em: $<$ wp.ufpel.edu.br/libertas/files/2014/09/SA_01306.pdf>. Acesso em: 05 jul. 2017.

DINIZ, Maria Helena. Dicionário Jurídico. São Paulo: Saraiva; 1998.

CUNHA, Rogério Sanches; PINTO, Ronaldo Batista. Violência doméstica: Lei Maria da Penha (Lei 11.340/2006), comentada, artigo por artigo - 2. ed. ver. Atual. e ampl. - São Paulo: Editora Revista dos Tribunais, 2012/2013.

FARIAS, Jean Ransley Oliveira; DINIZ, Ariosvaldo da Silva. Repercussões do inquérito policial na investigação criminal: desafios no combate à criminalidade no Brasil. Segurança Pública em Revista, v. 1, nº 1, p. 96-114, jan./jun. 2017.

FERREIRA FILHO, Manoel Gonçalves. Direitos humanos fundamentais - 6. ed. - São Paulo: Saraiva, 2010.

FRANCO, Michele Cunha. Determinantes do fluxo da justiça criminal: crimes de homicídio na cidade de Goiânia em 2007 e 2008. $8^{\circ}$ Encontro da ABCP; 01 a 04/08/2012, Gramado, RS. Área Temática: Segurança Pública e Segurança Nacional. Disponível em: $<$ https:/cienciapolitica.org.br/system/files/documentos/eventos/2017/02/determinantes-fluxojustica-criminal-crimes-homicidio-cidade.pdf > . Acesso em: 05 abr. 2017.

IPS. "Dossiê mulher 2016" / organizadores: Andréia Soares Pinto, Orlinda Claudia R. Moraes. Rio de Janeiro: Instituto de Segurança Pública, 2016.

JESUS, Damásio de. Código Penal Anotado. 9. ed. São Paulo: Saraiva, 1999.

LIMA, Fausto Rodrigues de. Dos procedimentos - artigos 13 a 17. In: CAMPOS, C. (org.). Lei Maria da Penha comentada na perspectiva jurídico-feminista. Rio de Janeiro: Lumen Juris, 2011.

LIMA FILHO. Altamiro de Araújo. Lei Maria da Penha Comentada - Leme/SP: Mundo Jurídico, 2011.

LIMA, Lana Lage da Gama; SOUZA, Fernando Carlos; SOUZA, Suellen André. Os desafios da Lei Maria da Penha como política pública de gênero. In: FAZENDO GÊNERO, 9. Florianópolis, 2010. Disponível em: 
$<$ http://www.fazendogenero.ufsc.br/9/resources/anais/1278354398_ARQUIVO_ArtigoFinal.p df $>$. Acesso em: 05 jul. 2017.

MACEDO, Y. M.; ALMEIDA, L. Q. de; PEDROSA, L. P. D. Vulnerabilidade social do Município de Natal, RN, Brasil: metodologia e aplicação. In: XIX SEMANA DE HUMANIDADES DA UFRN, 2011, Natal. XIX SEMANA DE HUMANIDADES DA UFRN, 2011. Disponível em: <http://www.cchla.ufrn.br/shXIX/anais/GT14/Artigo_GT14_shXIX.pdf>. Acesso em 01 de jul. 2017.

MEDEIROS, Fernando Antônio Carneiro de. Estimativa da População dos Bairros de Natal - 2016. Parque da Cidade em Revista. V. 2 - N I - Novembro de 2016. ISSN 24469254. ISSN 2447-0295 (online). Disponível em: <http://natal.rn.gov.br/semurb/revistas/edicoes/artigos/novembro2016/3_ESTIMATIVA_POP _2016.pdf>. Acesso em 01 de jul. 2017.

MEDEIROS, M. C. N. Núcleos de prevenção à violência. Relatório dos encontros do Núcleo de prevenção a Violência. Campina Grande, 2004.

MELLO, Adriana Ramos de; PAIVA, Lívia de Meira Lima; PINTO, Simone Cuber Araújo; GOÉS, Guilherme Sandoval; BAPTISTA, Michelly Ribeiro; FREITAS, Caroline Rocha; BRÜGGER, Vanessa Albuquerque; CAMPOS, Lígia. A resposta do Poder Judiciário às mulheres em situação de violência doméstica: um estudo das medidas protetivas de urgência no 'projeto violeta'. Revista da EMERJ, Rio de Janeiro, v. 20, n. 77, p. 211-233, jan. 2017. Artigo de revista. Disponível em: <http://bdjur.stj.jus.br/jspui/handle/2011/108226>. Acesso em 01 de jul. 2017.

MISSE, Michel. O inquérito Policial no Brasil: uma pesquisa empírica. $1^{\mathrm{o}}$ Ed. NEACVU/IFCS/UFRJ. Rio de Janeiro, 2010.

MORAES, Aparecida Fonseca; SORJ, Bila. Os paradoxos da expansão dos direitos das mulheres no Brasil. In: MORAES, Aparecida Fonseca; SORJ, Bila (coords.). Gênero, violência e direitos na sociedade brasileira. Rio de Janeiro: 7 letras, 2009.

OLIVEIRA, T. G.; TAVARES, M. S. As peculiaridades das mulheres em situação de violência doméstica e familiar e os desafios para sua proteção no âmbito da Rede de Atendimento. In: SCOTT, Parry; LYRA, Jorge; FONTE, Isolda Belo da. (Org.). Relações e Hierarquias marcadas por Gênero. 1 ed. Recife: Editora UFPE: UFRPE, 2016, v. 2, p. 87-100.

ORGANIZAÇÃO DOS ESTADOS AMERICANOS. Convenção Interamericana para Prevenir, Punir e Erradicar a Violência contra a Mulher - "Convenção de Belém do Pará". 1994. 
$<$ http://www.pge.sp.gov.br/centrodeestudos/bibliotecavirtual/instrumentos/belem.htm>. Acesso em: 30 mar. 2017.

PARODI, Ana Cecília; GAMA, Ricardo Rodrigues. Lei Maria da Penha - Comentários à Lei $\mathbf{n}^{\circ} \mathbf{1 1 . 3 4 0 / 2 0 0 6}-1^{\text {a }}$ ed. Campinas: Russel Editores, 2011/2012.

PASINATO, Wânia. Acesso à justiça e violência doméstica e familiar contra as mulheres: as percepções dos operadores jurídicos e os limites para a aplicação da Lei Maria da Penha. Rev. direito GV [online]. 2015, vol.11, n.2, pp.407-428. ISSN 1808-2432. Disponível em: <http://dx.doi.org/10.1590/1808-2432201518>. Acesso em 01 de jul. 2017.

PASINATO, Wânia. Violência contra as mulheres e legislação especial, ter ou não ter? Eis uma questão. Revista Brasileira de Ciências Criminais. São Paulo, Editora Revista dos Tribunais, n. 70, p. 321-360, jan.-fev. 2008.

RIFIOTIS, Theophilos; VENTURA, Andresa Burigo; CARDOSO, Gabriela Ribeiro. Reflexões críticas sobre a metodologia do estudo do fluxo de justiça criminal em casos de homicídios dolosos. Revista de Antropologia (USP. Impresso), v. 53, p. 689-714, 2010.

RIBEIRO, Ludimila; SILVA, Klarissa. Fluxo do Sistema de Justiça Criminal Brasileiro: Um balanço da literatura. In: Cadernos de Segurança Pública; Ano 2; Número 1; Agosto de 2010. Disponível em: <http://www.isp.rj.gov.br/revista/download/rev20100102.pdf>. Acesso em: 05 abr. 2017.

ROCHA, C. L. A. O direito a uma vida sem violência. In: LIMA, Fausto R.; SANTOS, Claudiene (Coords.). Violência doméstica: vulnerabilidades e desafios na intervenção criminal e multidisciplinar. 2. ed. Rio de Janeiro: Lumen Juris, 2010.

SABADELL, Ana Lucia. Manual de Sociologia Jurídica: introdução a uma leitura externa do Direito. 3. ed. São Paulo: Revista dos Tribunais, 2005.

SILVA, Elizabete Rodrigues da. Feminismo Radical - Pensamento e Movimento. Revista Travessias - Educação, Cultura, Linguagem e Arte, v. 2, n. 3, 2008.

VARGAS, Joana Domingues. Estupro: Que Justiça? Fluxo do Funcionamento e Análise do Tempo da Justiça Criminal para o Crime de Estupro. Instituto Universitário de Pesquisas do Rio de Janeiro (IUPERJ). Rio de Janeiro. Tese de Doutorado, 2004.

VARGAS, J.D \& RIBEIRO, L.M.L. Estudos de Fluxo da Justiça Criminal: Balanço e Perspectivas. $32^{\circ}$ Encontro Anual da ANPOCS. Caxambu, MG. 2008. 
VASCONCELLOS, Fernanda B. Delitos de proximidade e violência doméstica. In: LIMA, Renato Sérgio de; RATTON, José Luiz; AZEVEDO, Rodrigo Ghiringhelli de. (Org.). Crime, Polícia e Justiça no Brasil. 1. ed. São Paulo: Editora Contexto, 2014, v. 1, p. 293-298.

\title{
THE CRIME OF THREAT IN THE DOMESTIC FRAMEWORK: AN ANALYSIS OF THE IMPUNITY OF THE MARIA DA PENHA LAW FROM FLOW STUDIES
}

\begin{abstract}
The present study intends to identify which factors are preponderant in the flow of lawsuits in the 2nd Judgment of Domestic and Family Violence against Natal, Rio Grande do Norte, an institution that compose the criminal justice system, to assess the levels of impunity of the crime of threat when committed under the Maria da Penha Law. One of the main hypotheses that lead domestic violence cases to impunity is the possibility of retraction of the victim in the crimes in which such institutes are allowed, as is the case of the crime of threat. Another hypothesis is the slowness in the proceedings. From the methodological point of view, this work made use of the flow model to evaluate the functioning of the criminal justice system for the threat of domestic violence under a prospective longitudinal analysis. After data collection, tables were drawn up in order to graphically represent the results obtained. It was concluded that the victim's desistence in prosecuting the perpetrator represents an obstacle to the State's jus puniendi by withdrawing from the Judiciary Branch the possibility of provide a judicial service compatible with the aggression suffered, becoming a true circle of violence.
\end{abstract}

Keywords: Flow studies. Criminal Justice System. Domestic violence. Threat Crime. Impunity. 